\title{
Functional optical zone after wavefront-optimized versus wavefront-guided laser in situ keratomileusis
}

\author{
Mariam A Elshawarby ${ }^{1}$, Ali Saad ${ }^{1}$, Thanaa Helmy ${ }^{1}$, Mouamen M. Seleet ${ }^{1}$ and Tamer Elraggal ${ }^{1}$ \\ ${ }^{1}$ Ophthalmology Department, Ain Shams University Hospitals, Cairo, Egypt
}

\begin{abstract}
Background: Many studies have used functional optical zone (FOZ) as a measure to compare different refractive laser treatment modalities. However, to our knowledge, no study has compared wavefrontoptimized (WFO) and wavefront-guided (WFG) laser in situ keratomileusis (LASIK) using FOZ. We compared the FOZ after WFO versus WFG LASIK in patients with myopia and myopic astigmatism. Methods: In this prospective comparative study, we included 100 myopic eyes of 50 patients with or without astigmatism. They were divided into two groups according to the platform used: WFO or WFG femtosecond LASIK. Using Holladay's equivalent keratometry reading (EKR) report of Pentacam HR, FOZ was defined as a zone centered on the pupil center with a standard deviation (SD) of $0.5 \mathrm{D}$, around the mean EKR. The differences in FOZ between the two platforms were analyzed at 3 months postoperatively. Visual acuity, refractive error, corneal asphericity (Q-value), and root mean square of higher-order aberrations (RMS for HOAs) were evaluated and compared.

Results: The mean \pm SD of patient age was $26.64 \pm 5.67$ years. The preoperative characteristics of the two groups were comparable (all $P>0.05$ ). The intended optical zone (IOZ) was $6 \mathrm{~mm}$ in both groups. The mean laser ablation depth was significantly greater in the WFG group $(18 \mu \mathrm{m}$ per $\mathrm{D})$ than in the WFO group $(16 \mu \mathrm{m}$ per $\mathrm{D})(P=0.035)$. At 3 months postoperatively, the mean $\pm \mathrm{SD}$ of FOZ diameter was $4.32 \pm 0.94$ $\mathrm{mm}(71.99 \pm 15.68 \%$ of intended optical zone $)$ in the WFO group and $4.16 \pm 1.13 \mathrm{~mm}(69.33 \pm 18.78 \%$ of intended optical zone) in the WFG group, with no significant difference between the two groups $(P=$ $0.622)$. The change in corneal asphericity was greater in the WFG group than in the WFO group $(P=0.034)$. Postoperative mean corrected and uncorrected distance visual acuity, manifest refraction, and RMS for HOAs showed no significant difference between the two groups (all $P>0.05$ ).

Conclusions: We found that WFG LASIK resulted in greater ablation depth and change in corneal asphericity than WFO LASIK at 3 months postoperatively. However, there was no significant difference in FOZ diameter, refractive error, and RMS for HOAs between the two groups. Further research is needed to confirm these findings.
\end{abstract}

\section{KEYWORDS}

LASIK, laser in situ keratomileusis, wavefront-guided, wavefront-optimized, functional optical zone, intended optical zone, higher order aberrations, corneal asphericity

Correspondence: Mariam Elshawarby, Ophthalmology Department, Ain Shams University Hospitals, Ramses St., Cairo, Egypt.

Email: mariam10@med.asu.edu.eg. ORCID iD: https://orcid.org/0000-0002-2911-2933

How to cite this article: Elshawarby MA, Saad A, Helmy T, Seleet MM, Elraggal T. Functional optical zone after wavefront-optimized versus wavefront-guided laser in situ keratomileusis. Med Hypothesis Discov Innov Ophthalmol. 2021 Fall; 10(3): 129-137. https://doi.org/10.51329/mehdiophthal1431

Received: 13 August 2021; Accepted: 14 September 2021

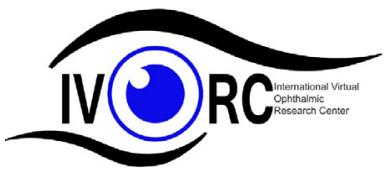

Copyright (C) Author(s). This is an open-access article distributed under the terms of the Creative Commons Attribution-NonCommercial 4.0 International License (http://creativecommons.org/licenses/by-nc/4.0/) which permits copy and redistribute the material just in noncommercial usages, provided the original work is properly cited. (c) () () 


\section{INTRODUCTION}

Conventional laser refractive surgery is effective for correcting simple spherocylindrical refractive errors. However, it changes corneal shape from a prolate to a more oblate profile, leading to greater higher-order aberrations (HOAs) and lower contrast sensitivity [1,2]. Wavefront-optimized (WFO) and wavefront-guided (WFG) platforms have been developed to compensate for this phenomenon [3]. The former applies more ablation to the periphery, considering the eye's refractive error and preoperative keratometry reading, while the latter offers a customized treatment plan that reduces both preoperative and postoperative HOAs. Many studies have shown that the two platforms are largely equivalent [4-7].

Not all intended optical zones (IOZs) provide functional vision $[8,9]$. According to Wachler et al., the functional optical zone (FOZ) is defined as the central part of the cornea with a high level of optical quality and fewer aberrations that could produce a potential visual acuity of 20/32 [10,11]. Many studies have used FOZ as a measure to compare different refractive laser treatment modalities [5, 6, 12-14]. Many methods have been suggested for its measurement; however, topography-based methods are the most practical because of their ease of implementation and direct spatial correspondence to corneal topographic maps [15].

Here, we aimed to compare the FOZ after WFO versus WFG LASIK for correction of myopia with or without astigmatism. The primary outcome measures were differences in FOZ between the two platforms, and the secondary outcome measures were uncorrected distance visual acuity (UCDVA), HOAs, and changes in corneal asphericity at 3 months postoperatively.

\section{METHODS}

In this prospective comparative study, we included 100 myopic eyes of 50 patients with or without astigmatism who underwent femtosecond LASIK using either the WFO or the WFG platform from June 2018 to December 2020. Ethical approval was obtained from the Ethical Review Committee of the Ain Shams University Faculty of Medicine, Cairo, Egypt. In accordance with the ethical standards stated by the Faculty of Medicine AinShams University and good clinical practice, written consent for participation and publication for the study was obtained prior to surgery.

We included patients ages 20 to 37 years who had stable refractive status (a change of $<0.50 \mathrm{D}$ in the spherical or cylindrical component over at least one year), a best-corrected distance visual acuity (BCDVA) 20/20 using Snellen's visual acuity chart, myopia (range: $-1.00 \mathrm{D}$ to $-6.00 \mathrm{D}$ ) with or without myopic astigmatism (range: $0.00 \mathrm{D}$ to $-3.00 \mathrm{D}$ ), a healthy cornea, a mesopic pupil diameter $\leq 6 \mathrm{~mm}$, and corneal thickness $\geq 500$ $\mu \mathrm{m}$ (with an estimated residual stromal bed thickness $>300 \mu \mathrm{m}$ ). Patients with unstable refraction, hyperopia, myopia greater than $-6.00 \mathrm{D}$ and astigmatism greater than $-3.00 \mathrm{D}$, eyelid abnormalities, moderate to severe meibomian gland dysfunction, corneal opacities, corneal basement membrane dystrophies, a history of herpes keratitis, a suspicious corneal topography, ectatic corneal diseases (i.e., keratoconus, forme fruste keratoconus, or pellucid marginal degeneration), diabetes mellitus, collagen vascular diseases, an immunocompromised status, autoimmune diseases, and those who were pregnant or lactating or taking medications such as antihypertensives (e.g., propranolol), isotretinoin, oral contraceptive pills, and psychiatric medications were excluded.

The preoperative evaluation included medical (including ophthalmic), medication, and family history, and a history of using spectacles or contact lenses. Contact lenses were removed (7 days for soft non-toric, 14 days for soft toric, and 1 month for every decade of use for rigid gas-permeable contact lenses) prior to the preoperative evaluation. UCDVA and BCDVA were measured using Snellen's chart and expressed as decimal values. Manifest and cycloplegic refraction were measured using an autorefractometer (ARK-1 Auto Ref/Keratometer; Nidek Co., Ltd., Japan). Slit lamp examination was performed with an SL-3G slit lamp (Topcon Co., Tokyo, Japan), followed by fundus biomicroscopy with a noncontact lens +90 D (Volk Optical Inc., Mentor, OH, USA) and applanation tonometry with a Goldmann tonometer (AT $900 \mathrm{C} / \mathrm{M}$; HaagStreit, Bern, Switzerland) after obtaining axial/sagittal curvature maps, pachymetry maps, corneal surface asphericity, pupil size, and corneal regularity indices (index of surface variance [ISV] and index of height decentration [IHD]) using a Pentacam HR (Oculus Optikgeräte GmbH, Wetzlar, Germany).

Patients were divided into two groups according to the platform used for LASIK: WFO or WFG. All had a fixed IOZ of $6 \mathrm{~mm}$. WFO LASIK was performed at the Watany Eye Hospital, Cairo, Egypt (by Elraggal T.). LASIK flaps were made with a WaveLight ${ }^{\circledR}$ FS200 laser (Alcon Laboratories, Inc., Fort Worth, TX, USA), and ablation was performed using the WaveLight ${ }^{\circledast}$ EX500 excimer laser system (Alcon, Inc., Huenberg, Switzerland). WFG LASIK was performed at Magrabi Eye Hospital, Cairo, Egypt (by Seleet M.). All eyes 
underwent preoperative wavefront analysis using the VISX CustomVue WaveScan aberrometer v.3.62 (Fourier) (Advanced Medical Optics, Santa Ana, CA, USA). LASIK flaps were made with IntraLase iFS (Johnson \& Johnson Inc., Santa Ana, CA, USA), and ablation was performed using the VISX CustomVue ${ }^{\mathrm{Tx}}$ STAR S4 IR ${ }^{\mathrm{Tm}}$ Excimer Laser (Johnson \& Johnson Inc., Santa Ana, CA, USA) with Active-Track ${ }^{\mathrm{Tx}}$ iris registration.

Postoperatively, all patients were prescribed topical dexamethasone $0.1 \%+$ tobramycin $0.3 \%$ (Tobradex; Alcon, Fort Worth, TX, USA) eye drops 6 times/day for 1 week, plus artificial tears (Systane ${ }^{\varpi}$ Ultra Lubricant Eye Drops; Alcon, Fort Worth, TX, USA) 6 times/day for 1 month. Routine follow-up visits were performed the next day and at 1 week and 3 months postoperatively. In the last follow-up visit at 3 months, we measured UCDVA and BCDVA using Snellen's chart and expressed as decimal values. Manifest and cycloplegic refraction were measured. Intraocular pressure was checked using air-puff tonometry (Topcon CT-80 Computerized Auto Tonometer; Topcon, Tokyo, Japan), and slit lamp biomicroscopy was used for anterior segment examination to ensure the flap was in place and to look for any signs of late-onset complications (e.g., dry eye and ectasia). Fundus biomicroscopy was performed with a Volk 90D lens after pupillary dilatation. Axial/sagittal curvature maps, pachymetry maps, corneal surface asphericity, and corneal regularity indices were obtained using Pentacam HR. FOZ and corneal front surface wavefront aberrations such as root mean square of higher-order aberrations (RMS for HOAs) and spherical aberration Zernike coefficient (Z40) were measured and compared between the two groups using tomography-based Scheimpflug imaging (Pentacam HR).

To measure the FOZ, we chose Holladay's equivalent keratometry reading (EKR) report (power map) of Pentacam HR. Our aim was to determine the area in the central cornea with uniform refractive power $( \pm 0.5$ $D)$, indicative of an effective treatment [11]. The measurement steps were as follows. (1) We set the size of the calculation zone at a zonal diameter of $6 \mathrm{~mm}$. (2) We chose Holladay zone centered on the pupil center with a zonal standard deviation (SD) nearest to $0.5 \mathrm{D}$ around the mean EKR. This threshold value of $0.5 \mathrm{D}$ was chosen, as UCDVA of 20/32, which results from a $-0.5 \mathrm{D}$ defocus, does not interfere with daily life activities $[10,14,16]$. (3) We recorded the Holladay zonal diameter that met these criteria as the diameter of FOZ (Figure 1).

Data were gathered, revised, coded, and uploaded to the Statistical Package for the Social Sciences (IBM SPSS Statistics for Windows, version 23.0; IBM Corp., Armonk, NY, USA). Comparisons between groups were performed using the independent $t$-test and the Mann-Whitney test. The Kolmogorov-Smirnov test

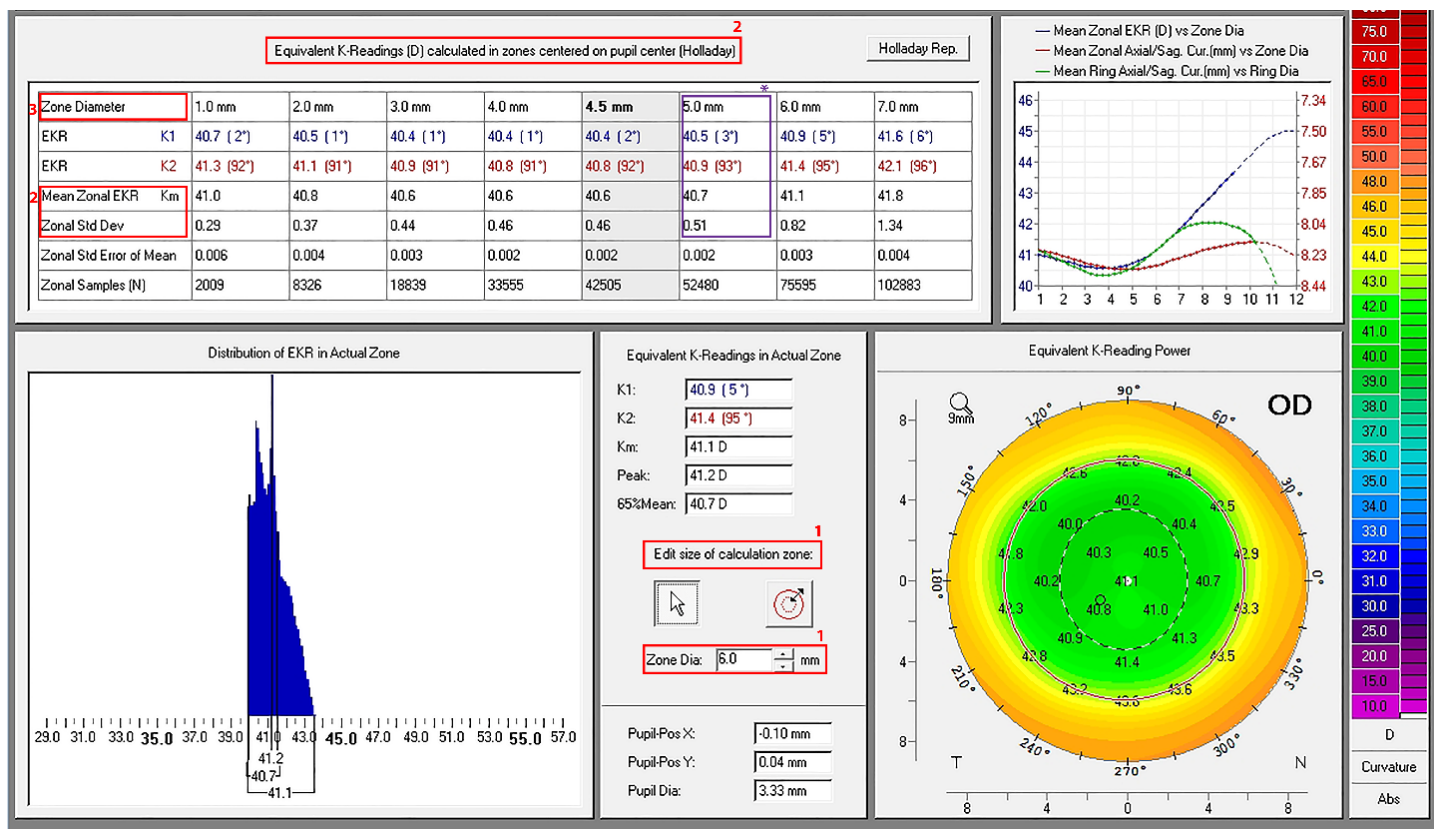

Figure 1. A sample Pentacam HR image showing how the functional optical zone (FOZ) was measured postoperatively. (1) The size of the calculation zone was set at a zonal diameter of $6 \mathrm{~mm}$. (2) The Holladay zone was centered on the pupil center with a zonal standard deviation (SD) nearest to $0.5 \mathrm{D}$ around the mean EKR $[10,14,16]$. Finally, the Holladay zonal diameter that met these criteria was recorded as the diameter of FOZ. Here, when Zonal diameter set to $6 \mathrm{~mm}(1)$, the mean EKR of $40.7 \mathrm{~mm}$ with an SD of $0.5 \mathrm{D}$ (2) showing a FOZ diameter of $5 \mathrm{~mm}(3)$. 
was used to assess the normality of the data, and Spearman's rank correlation coefficient was used to calculate the correlation. The confidence level was set at $95 \%$, and the accepted margin of error was set at $5 \%$. Statistical significance was set at $P<0.05$, and a $P<0.01$ was considered to be highly significant.

\section{RESULTS}

We included 50 patients with a mean \pm SD age of $26.64 \pm 5.67$ years. Twenty-three (46\%) were men and 27 (54\%) were women. As shown in Table 1, preoperative and intraoperative parameters were comparable between the two groups (all $P>0.05$ ), except for the mean maximal laser ablation depth, which was significantly greater in the WFG group than in the WFO group $(P=0.035)$. All surgeries were uneventful with an IOZ of $6 \mathrm{~mm}$, a flap diameter ranging from 8.7 to $9 \mathrm{~mm}$, and a flap thickness ranging from 90 to $120 \mu \mathrm{m}$ (Table 1 ).

Outcomes for the last follow-up visit at 3 months are illustrated in Table 2. Changes in corneal asphericity $(\Delta \mathrm{Q})$ were significantly greater in the WFG group than in the WFO group $(P=0.034)$ (Table 2). The UCDVA, BCDVA, spherical equivalent of manifest refraction (SE), maximum keratometric power (Kmax), thinnest location, RMS for HOAs, and Z40 were not different between the two groups (all $P>0.05$ ) (Table 2 ) and neither were FOZ measurements $(P=0.622)$ (Table 3$)$. A positive correlation was found between FOZ diameter and postoperative corneal thickness $(\mathrm{r}=+0.295 ; P=0.038$ for WFO, $\mathrm{r}=+0.487 ; P<0.001$ for WFG) and a negative correlation between FOZ diameter and maximal laser ablation depth $(\mathrm{r}=-0.626 ; P$ $<0.001$ for WFO, $\mathrm{r}=-0.475 ; P<0.001$ for WFG), and RMS for HOAs $(\mathrm{r}=-0.533 ; P<0.001$ for WFO, $\mathrm{r}=$ $-0.506 ; P<0.001$ for WFG).

Table 1. Preoperative and intraoperative parameters in the WFO and WFG LASIK groups

\begin{tabular}{|c|c|c|c|}
\hline Preoperative data & $\begin{array}{l}\text { Group A } \\
\mathbf{n}=\mathbf{5 0}\end{array}$ & $\begin{array}{l}\text { Group B } \\
\mathbf{n}=\mathbf{5 0}\end{array}$ & $P$-value \\
\hline UCDVA (decimal), Mean \pm SD (Range) & $0.44 \pm 0.13(0.2$ to 0.7$)$ & $0.47 \pm 0.14(0.2$ to 0.7$)$ & 0.426 \\
\hline BCDVA (decimal), Mean \pm SD (Range) & $0.99 \pm 0.03(0.9$ to 1$)$ & $1.00 \pm 0.02(0.9$ to 1$)$ & 0.143 \\
\hline Sphere (D), Mean \pm SD (Range) & $-3.84 \pm 1.28(-6$ to -1.75$)$ & $-4.14 \pm 1.42(-6$ to -1.75$)$ & 0.242 \\
\hline Cylinder (D), Mean \pm SD (Range) & $-1.24 \pm 1.00(-3$ to 0.00$)$ & $-0.84 \pm 0.44(-1.75$ to -0.25$)$ & 0.213 \\
\hline SE $(D)$, Mean \pm SD $($ Range $)$ & $-4.45 \pm 1.48(-7.5$ to -2.25$)$ & $-4.56 \pm 1.39(-6.63$ to -2.13$)$ & 0.400 \\
\hline K1 (D), Mean \pm SD $($ Range $)$ & $43.03 \pm 1.74(39.61$ to 45.9$)$ & $42.27 \pm 1.69(39.5$ to 45.8$)$ & 0.079 \\
\hline K2 (D), Mean \pm SD (Range) & $44.35 \pm 1.68(40.8$ to 46.87$)$ & $43.29 \pm 1.53(40.5$ to 46.3$)$ & 0.056 \\
\hline Kmean (D), Mean \pm SD (Range) & $43.70 \pm 1.66(40.5$ to 46.1$)$ & $42.79 \pm 1.58(40$ to 46$)$ & 0.061 \\
\hline Kmax (D), Mean \pm SD (Range) & $44.78 \pm 1.57(41.2$ to 46.95$)$ & $43.77 \pm 1.56(40.6$ to 46.9$)$ & 0.091 \\
\hline Pachy apex $(\mu \mathrm{m})$, Mean \pm SD $($ Range $)$ & $570.04 \pm 41.66(524$ to 648$)$ & $566.32 \pm 28.57(523$ to 619$)$ & 0.594 \\
\hline Thinnest location $(\mu \mathrm{m})$, Mean \pm SD $($ Range $)$ & $565.46 \pm 41.56(520$ to 643$)$ & $562.10 \pm 29.44(514$ to 616$)$ & 0.604 \\
\hline ISV, Mean \pm SD (Range) & $18.36 \pm 3.70(13$ to 26$)$ & $15.56 \pm 2.54(11$ to 21$)$ & 0.642 \\
\hline IHD, Mean \pm SD (Range) & $0.007 \pm 0.003(0.004$ to 0.015$)$ & $0.008 \pm 0.004(0.003$ to 0.014$)$ & 0.063 \\
\hline Qvalue, Mean \pm SD (Range) & $-0.25 \pm 0.03(-0.32$ to -0.21$)$ & $-0.26 \pm 0.05(-0.38$ to -0.16$)$ & 0.058 \\
\hline PD $(\mathbf{m m})$, Mean \pm SD $($ Range $)$ & $2.78 \pm 0.32(2.32$ to 3.89$)$ & $3.29 \pm 0.57(2.36$ to 4.4$)$ & 0.056 \\
\hline Intraoperative data & $\begin{array}{l}\text { Group A } \\
\mathbf{n}=\mathbf{5 0}\end{array}$ & $\begin{array}{l}\text { Group B } \\
\mathbf{n}=\mathbf{5 0}\end{array}$ & $P$-value \\
\hline Flap thickness $(\mu \mathrm{m})$, Mean \pm SD $($ Range $)$ & $110.80 \pm 4.88(100$ to 120$)$ & $90.00 \pm 0.00(90$ to 90$)$ & 0.051 \\
\hline Flap diameter $(\mathbf{m m})$, Mean \pm SD $($ Range $)$ & $8.76 \pm 0.09(8.7$ to 9$)$ & $8.85 \pm 0.14(8.7$ to 9$)$ & 0.053 \\
\hline Side cut angle (degree), Mean \pm SD (Range) & $120.00 \pm 0.00(120$ to 120$)$ & $120.00 \pm 0.00(120$ to 120$)$ & 0.642 \\
\hline IOZ $(\mathbf{m m})$, Mean \pm SD $($ Range $)$ & $6.00 \pm 0.00(6$ to 6$)$ & $6.00 \pm 0.00(6$ to 6$)$ & 0.542 \\
\hline MAD $(\mu \mathrm{m})$, Mean \pm SD $($ Range $)$ & $71.80 \pm 21.65(42.05$ to 118$)$ & $81.81 \pm 24.97(38$ to 118.8$)$ & 0.035 \\
\hline $\mathrm{RST}(\mu \mathrm{m})$, Mean $\pm \mathrm{SD}($ Range $)$ & $373.44 \pm 33.72(345$ to 460$)$ & $370.14 \pm 39.46(324$ to 468$)$ & 0.654 \\
\hline
\end{tabular}

Abbreviations: n, number; UCDVA, uncorrected distance visual acuity; BCDVA, best-corrected distance visual acuity; SD, standard deviation; sphere, spherical component of manifest refraction; cylinder, cylindrical component of manifest refraction; SE, spherical equivalent of manifest refraction; D, diopter; K1, the steepest corneal meridian; K2, the flattest corneal meridian; Kmean, mean keratometric power; Kmax, maximum keratometric power; Pachy apex, corneal thickness at the apex; $\mu$ m, micrometer; thinnest location, thinnest point over the anterior corneal surface; ISV, index of surface variance; IHD, index of height decentration; Q-value, corneal asphericity; PD, pupil diameter; mm, millimeter; IOZ, intended optical zone; MAD, maximal ablation depth; RST, residual stromal thickness; LASIK, laser in situ keratomileusis. Values of $P<0.05$ are shown in bold. Note: K1, K2, Kmean, Kmax, pachy apex, thinnest location, ISV, IHD, Q-value, and pupil diameter were measured using Pentacam HR (Oculus Optikgeräte GmbH, Wetzlar, Germany). Group A, wavefront-optimized (WFO); Group B, wavefrontguided (WFG). 
Table 2. Outcomes at 3 months after WFO or WFG LASIK

\begin{tabular}{|c|c|c|c|}
\hline Postoperative data & $\begin{array}{l}\text { Group A } \\
\mathbf{n}=\mathbf{5 0}\end{array}$ & $\begin{array}{l}\text { Group B } \\
\mathbf{n}=\mathbf{5 0}\end{array}$ & $P$-value \\
\hline UCDVA (decimal), Mean \pm SD (Range) & $0.94 \pm 0.09(0.8$ to 1$)$ & $0.96 \pm 0.08(0.8$ to 1$)$ & $0.236^{*}$ \\
\hline BCDVA (decimal), Mean \pm SD (Range) & $1.00 \pm 0.00(1$ to 1$)$ & $1.00 \pm 0.00(1$ to 1$)$ & $1.000 *$ \\
\hline SE (D), Median (IQR), (Range) & $0(-0.25$ to 0$),(-0.5$ to 0.00$)$ & $0(0$ to 0$),(-0.5$ to 0.00$)$ & $0.137^{* *}$ \\
\hline K1, Mean \pm SD $($ Range $)$ & $39.38 \pm 2.11(36$ to 43.3$)$ & $38.45 \pm 1.50(35.9$ to 41.2$)$ & $0.013 *$ \\
\hline K2, Mean \pm SD (Range) & $39.93 \pm 2.06(36.3$ to 43.8$)$ & $39.03 \pm 1.47(36.6$ to 41.7$)$ & $0.013 *$ \\
\hline Kmax, Mean \pm SD (Range) & $43.31 \pm 1.53(40.5$ to 46$)$ & $43.12 \pm 2.10(39$ to 47$)$ & $0.602 *$ \\
\hline Thinnest Location, Mean \pm SD (Range) & $481.34 \pm 44.86(409$ to 574$)$ & $480.14 \pm 39.46(434$ to 578$)$ & $0.887 *$ \\
\hline RMS for HOA, Median (IQR), (Range) & 0.69 (0.6 to 0.88$),(0.47$ to 1.49$)$ & $0.7(0.58$ to 0.89$),(0.29$ to 1.21$)$ & $0.863 * *$ \\
\hline SA $(Z 40)$, Mean \pm SD $($ Range $)$ & $0.53 \pm 0.11(0.23$ to 0.81$)$ & $0.55 \pm 0.20(0.24$ to 0.93$)$ & $0.578 *$ \\
\hline $\begin{array}{l}\Delta Q \text { value (postoperative -postoperative) } \\
\text { Mean } \pm \text { SD }\end{array}$ & $0.79 \pm 0.42$ & $0.96 \pm 0.37$ & $0.034 *$ \\
\hline
\end{tabular}

Abbreviations: n, number; UCDVA, uncorrected distance visual acuity; BCDVA, best-corrected distance visual acuity; SD, standard deviation; SE, spherical equivalent; D, diopter; IQR, interquartile range; K1, steepest corneal meridian; K2, flattest corneal meridian; Kmax, maximum keratometric power; Thinnest location, thinnest point over the anterior corneal surface; RMS for HOA, root mean square for higher-order aberrations; SA (Z40), spherical aberration Zernike coefficient Z40; $\Delta Q$ value, change in corneal asphericity; LASIK, laser in situ keratomileusis. Values of $P<0.05$ are shown in bold. *Independent $t$-test; ** Mann-Whitney test. Note: Group A, wavefront-optimized (WFO); Group B, wavefront-guided (WFG).

Table 3. FOZ and IOZ changes after WFO or WFG LASIK

\begin{tabular}{|l|l|l|l|}
\hline Variable & $\begin{array}{l}\text { Group A } \\
\mathbf{n = 5 0}\end{array}$ & $\begin{array}{l}\text { Group B } \\
\mathbf{n = 5 0}\end{array}$ & $4.16 \pm 1.13(3$ to 6$)$ \\
\hline FOZ diameter (mm), Mean \pm SD (Range) & $4.32 \pm 0.94(3$ to 6$)$ & $39.78 \pm 2.08(36.2$ to 43.8$)$ & $<.622$ \\
\hline Mean zonal EKR(D), Mean \pm SD (Range) & $38.21 \pm 1.55(34.99$ to 41.04$)$ & $1.84 \pm 1.13(0$ to 3$)$ & 0.254 \\
\hline IOZ Changes (mm), Mean \pm SD (Range) & $1.68 \pm 0.94(0$ to 3$)$ & $69.33 \pm 18.78(50$ to 100$)$ & 0.443 \\
\hline FOZ\% achieved, Mean \pm SD (Range) & $71.99 \pm 15.68(50$ to 100$)$ & \\
\hline
\end{tabular}

Abbreviations: FOZ, functional optical zone; SD, standard deviation; EKR, Holladay Equivalent K Reading; D, diopter; IOZ, intended optical zone; IOZ changes, IOZ - FOZ; LASIK, laser in situ keratomileusis. Values of $P<0.05$ are shown in bold. * Independent t-test. Note: Group A, wavefront-optimized (WFO); Group B, wavefront-guided (WFG).

\section{DISCUSSION}

There was no significant difference between the WFO and WFG LASIK groups in terms of FOZ size, refractive outcomes, RMS for HOAs, and spherical aberration (Zernike coefficient Z40) at 3 months postoperatively. The mean maximal laser ablation depth and change in corneal asphericity $(\Delta Q)$ were significantly greater in the WFG group than in the WFO group.

Many studies have compared the efficacy of WFO and WFG platforms for myopic correction and concluded that the two yield largely equivalent outcomes $[4,17]$. These studies are summarized in Table $4[3-6,17-24]$. FOZ has also been used as an effective tool for the assessment and comparison of different laser refractive surgery modalities $[8,9]$. However, to our knowledge, no study has compared WFG and WFO LASIK using FOZ.

In our study, tomography-based Scheimpflug imaging (Pentacam HR) was chosen to measure FOZ, as done by Hou et al. [13] and Ding et al. [14]; however, our data were collected from Holladay's detailed report, not from the tangential curvature difference map or the total corneal refractive power (TCRP) map. We used a change of corneal powers within the $\pm 0.5 \mathrm{D}$ range around the mean EKR. Racine et al. [25] used $\pm 0.5 \mathrm{D}$ change of powers from the pupil center, Tabernero et al. [15] used a $\pm 0.5 \mathrm{D}$ range for the statistical mode, and Ding et al. [14] used points that reached a corneal apex refractive power of + 0.5 D. In our method, FOZ measurements were directly obtained from the scans without the need to use formulas and calculations.

In our study, following WFG LASIK, the mean FOZ diameter was $4.16 \mathrm{~mm}$, representing $69.33 \%$ of IOZ $(P<0.05)$. This result was similar to that of Racine et al. [25], where following CustomVue LASIK, mean FOZ diameters (long and short axes) were $5.35 \mathrm{~mm}$ and $4.26 \mathrm{~mm}$ when compared to the programmed OZ 


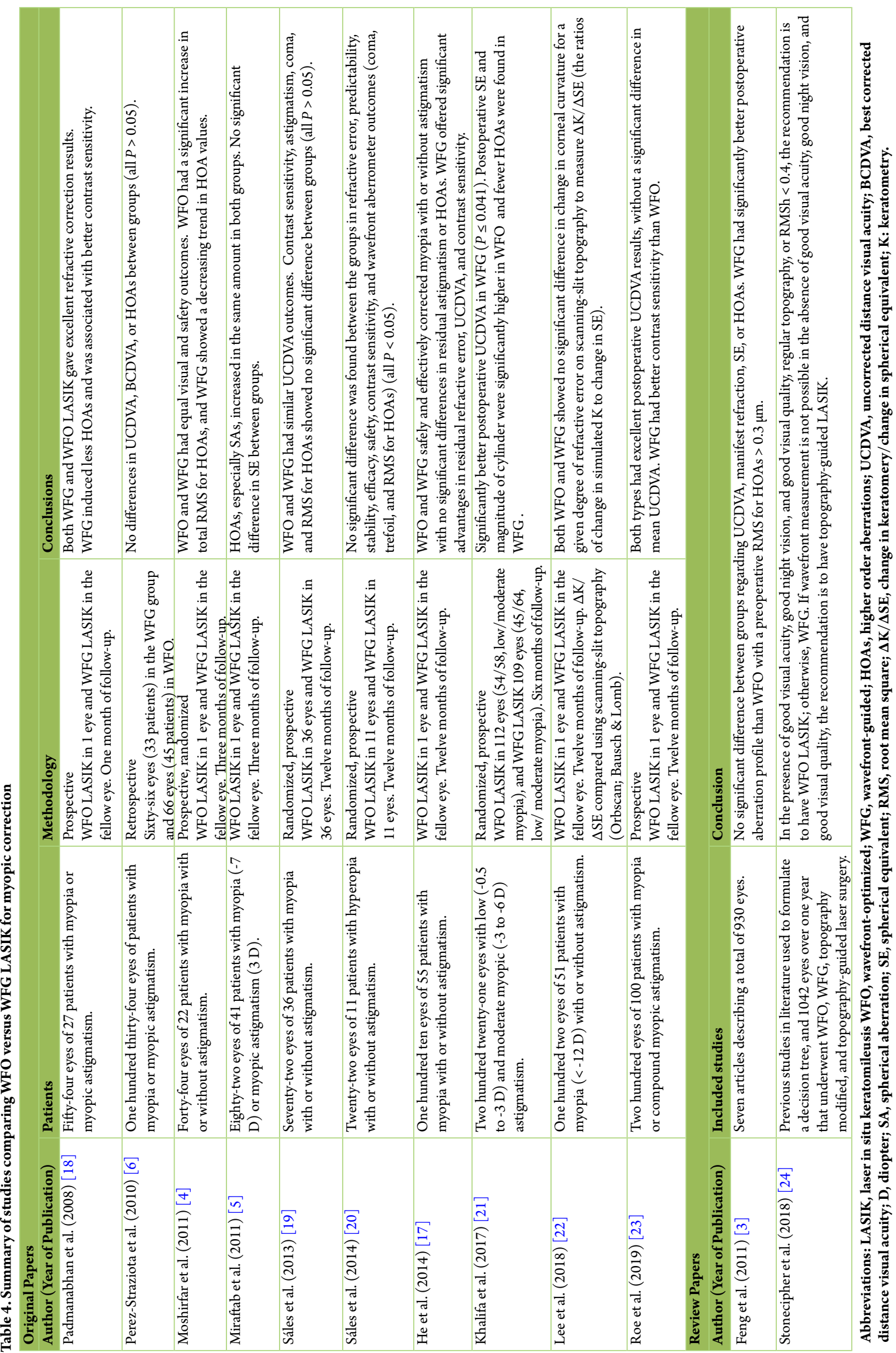


diameters of $6.39 \mathrm{~mm}$ and $6 \mathrm{~mm}$, representing 59.58\% of the laser-programmed OZ $(P<0.0001)[25]$. Concerning WFO ablation, our study showed a decrease in the FOZ (mean diameter of $4.32 \mathrm{~mm}$ compared to the IOZ of $6 \mathrm{~mm})$, with a mean difference of $-1.68 \mathrm{~mm}$ between them $(P<0.05)$. This was different from the results of Danasoury et al. [11], where optimized prolate ablation (NIDEK laser platform) with a programmed OZ $(6.80 \mathrm{~mm})$ resulted in a larger FOZ with a mean difference between its horizontal diameter and the programmed $\mathrm{OZ}$ of $+0.377 \mathrm{~mm}$ [11]. This discrepancy may be due to a different method (corneal topography axial map with the Klyce-Smolek scale and color scheme) that was used to manually measure FOZ with a $1.50 \mathrm{D}$ change from the central corneal power [26]. In our study, both LASIK platforms (WFO and WFG) yielded a decrease in FOZ size when compared with IOZ, which was similar to results reported after conventional myopic LASIK surgery by Holladay and Janes [12] and Partal and Manche [27]. In our study, the difference in FOZ between WFO and WFG was not significant $(P=0.622)$. In our study, both groups demonstrated a significant negative correlation between FOZ diameter and maximal laser ablation depth and a significant positive correlation between FOZ diameter and postoperative corneal thickness (all $P<0.05$ ). These findings confirmed the results of Boxer Wachler et al. [10] and El Danasoury et al. [11], but were unlike those of Racine et al. [25], who showed that FOZ did not decrease significantly with increasing amount of refractive correction. This controversy may be attributed to different ways of measuring FOZ, with the actual shape of most measured zones not fulfilling an exact ellipse.

Concerning the visual outcomes, both groups in our study achieved excellent refractive outcomes with no significant difference between them. This agrees with the results of Perez-Straziota et al. [6], Meidani and Tzavara [28], Hassan et al. [29], and Mahmoud et al. [30]. On the other hand, our results were different from those reported by He et al. [17], Ghoneim et al. [31], and Roe and Manche [23], where WFG appeared to be superior to WFO $(P=0.016)$. This can be explained by the contralateral-eye design, which eliminates confounding factors specific to individual patients, such as wound healing and corneal mechanical properties. In our study, postoperative RMS for HOAs and spherical aberration Zernike coefficient (Z40) showed no significant differences between the two groups. This was also observed previously by Roe and Manche [23], He et al. [17], Reed et al. [32], and Mahmoud et al. [30]. However, Moshirfar et al. [4], Khalifa et al. [21], and Ghoneim et al. [31] found that the level of induced HOAs was significantly higher in the WFO group than in the WFG group, which could be attributed to their use of high-resolution aberrometer measurements to define WFG ablation profiles $[4,21,31]$. Concerning the change in corneal asphericity, our results were similar to those of Bottos et al. [33] and Molchan et al. [34], where $\Delta Q$ was significantly greater in the WFG group than in the WFO group ( $P$ $=0.034)$. The mean maximal laser ablation depth in our study was greater in the WFG group than in the WFO group $(P=0.035)$. This finding is consistent with that reported by $\mathrm{He}$ et al. [17].

To our knowledge, our study is the first to compare WFG and WFO LASIK using FOZ. There was no significant difference between the two groups. The limitations of this study included a relatively small number of patients, excluding myopes with more than $6 \mathrm{D}$ of refractive error, a short follow-up period, and interoperator variability between both groups. We recommend a contralateral-eye design and larger-scale studies with longer follow-up periods to confirm our results. Further studies are needed to develop a universal method for measuring topographic FOZ.

\section{CONCLUSIONS}

We found that WFG LASIK resulted in greater ablation depth and change in corneal asphericity than WFO LASIK at 3 months postoperatively. However, there was no significant difference in FOZ diameter, refractive error, and RMS for HOAs between the two groups. Further research is needed to confirm these findings.

\section{ETHICAL DECLARATIONS}

Ethical approval: Ethical approval was obtained from the Ethics Review Committee of Ain Shams University, Cairo, Egypt. In accordance with the ethical standards stated by the Faculty of Medicine Ain-Shams University and good clinical practice, written consent for participation and publication for the study was obtained prior to surgery.

Conflict of interest: None.

\section{FUNDING}

\section{None.}




\section{ACIRNOWLED GEMENT}

This work is part of a project entitled "Comparison between wavefront-guided and wavefront-optimized LASIK with regards to the functional optical zone."

\section{REFERENCES}

1. Padmanabhan P, Basuthkar S, Joseph R. Ocular aberrations after wavefront optimized LASIK for myopia. Indian Journal of Ophthalmology. 2010;58(4):307-12. doi: 10.4103/0301-4738.64139 pmid: 20534921

2. Chalita M, Chavala S, Xu M, Krueger RR. Wavefront analysis in post-LASIK eyes and its correlation with visual symptoms, refraction, and topography. Ophthalmology. 2004;111(3):447-53. doi: 10.1016/j.ophtha.2003.06.022 pmid: 15019317

3. Feng Y, Yu J, Wang Q. Meta-Analysis of Wavefront-Guided vs. Wavefront-Optimized LASIK for Myopia. Optometry and Vision Science. 2011;88(12):1463-9. doi: 10.1097/OPX.0b013e3182333a50 pmid: 21946784

4. Moshirfar M, Betts, Churgin, Maylon H, Neuffer M, Sikder, et al. A prospective, randomized, fellow eye comparison of WaveLight\&reg; Allegretto Wave\&reg; Eye-Qversus VISX CustomVue\&trade; STAR S4 IR\&trade; in laser in situ keratomileusis (LASIK): analysis of visual outcomes and higher order aberrations. Clinical Ophthalmology. 2011;5:1339-47. doi: 10.2147/ OPTH.S24316 pmid: 22034553

5. Miraftab M, Seyedian MA, Hashemi H. Wavefront-Guided vs Wavefront-Optimized LASIK: A Randomized Clinical Trial Comparing Contralateral Eyes. Journal of Refractive Surgery. 2011;27(4):245-50. doi: 10.3928/1081597X-20100812-02 pmid: 20839665

6. Perez-Straziota CE, Randleman BJ, Stulting DR. Visual acuity and higher-order aberrations with wavefront-guided and wavefront-optimized laser in situ keratomileusis. Journal of Cataract and Refractive Surgery. 2010;36(3):437-41. doi: 10.1016/j. jcrs.2009.09.031 pmid: 20202542

7. Yu J, Chen H, Wang F. Patient Satisfaction and Visual Symptoms After Wavefront-guided and Wavefront-optimized LASIK With the WaveLight Platform. Journal of Refractive Surgery. 2008;24(5):477-86. doi: 10.3928/1081597X-20080501-05 pmid: 18494340

8. Wang L, Shoss BL, Weikert MP, Koch DD. Ocular Functional Optical Zone Changes Following Wavefront-Guided LASIK/PRK. Investigative Ophthalmology \& Visual Science. 2010 Apr 17;51(13):4212. Link

9. Damgaard IB, Ang M, Mahmoud AM, Farook M, Roberts CJ, Mehta JS. Functional Optical Zone and Centration Following SMILE and LASIK: A Prospective, Randomized, Contralateral Eye Study. Journal of Refractive Surgery. 2019;35(4):230-7. doi: 10.3928/1081597X-20190313-01 pmid: 30984980

10. Boxer Wachler BS, Huynh VN, El-Shiaty AF, Goldberg D. Evaluation of corneal functional optical zone after laser in situ keratomileusis. Journal of Cataract and Refractive Surgery. 2002;28(6):948-53. doi: 10.1016/s0886-3350(02)01322-6 pmid: 12036635

11. El Danasoury AM, Holladay J, Waring GO, Pieger S, Bains HS. A Contralateral, Randomized Comparison of Optimized Prolate Ablation and Conventional LASIK for Myopia With the NIDEK Excimer Laser Platform. Journal of Refractive Surgery. 2012;28(7):453-61. doi: 10.3928/1081597X-20120621-01 pmid: 22767164

12. Holladay JT, Janes JA. Topographic changes in corneal asphericity and effective optical zone after laser in situ keratomileusis. Journal of Cataract and Refractive Surgery. 2002;28(6):942-7. doi: 10.1016/s0886-3350(02)01324-x pmid: 12036634

13. Hou J, Wang Y, Lei Y, Zheng X. Comparison of effective optical zone after small-incision lenticule extraction and femtosecond laser-assisted laser in situ keratomileusis for myopia. Journal of Cataract and Refractive Surgery. 2018;44(10):1179-85. doi: 10.1016/j.jcrs.2018.06.046 pmid: 30243392

14. Ding X, Fu D, Wang L, Zhou X, Yu Z. Functional Optical Zone and Visual Quality After Small-Incision Lenticule Extraction for High Myopic Astigmatism. Ophthalmology and Therapy. 2021;10(2):273-88. doi: 10.1007/s40123-021-00330-9 pmid: 33548046

15. Tabernero J, Klyce SD, Sarver EJ, Artal P. Functional Optical Zone of the Cornea. Investigative Opthalmology \& Visual Science. 2007;48(3):1053-60. doi: 10.1167/iovs.06-0867 pmid: 17325146

16. Nepomuceno RL, Boxer Wachler BS, Scruggs R. Functional optical zone after myopic LASIK as a function of ablation diameter. Journal of Cataract and Refractive Surgery. 2005;31(2):379-84. doi: 10.1016/j.jcrs.2004.04.073 pmid: 15767162

17. He L, Liu A, Manche EE. Wavefront-Guided Versus Wavefront-Optimized Laser in situ Keratomileusis for Patients With Myopia: A Prospective Randomized Contralateral Eye Study. American Journal of Ophthalmology. 2014;157(6):1170-8.e1. doi: 10.1016/j. ajo.2014.02.037 pmid: 24560995

18. Padmanabhan P, Mrochen M, Basuthkar S, Viswanathan D, Joseph R. Wavefront-guided versus wavefront-optimized laser in situ keratomileusis: Contralateral comparative study. Journal of Cataract and Refractive Surgery. 2008;34(3):389-97. doi: 10.1016/j. jcrs.2007.10.028 pmid: 18299062

19. Sáles CS, Manche EE. One-Year Outcomes from a Prospective, Randomized, Eye-to-Eye Comparison of Wavefront-Guided and Wavefront-Optimized LASIK in Myopes. Ophthalmology. 2013;120(12):2396-402. doi: 10.1016/j.ophtha.2013.05.010 pmid: 23778091

20. Sales C, Manche E. One-year eye-to-eye comparison of wavefront-guided versus wavefront-optimized laser in situ keratomileusis in hyperopes. Clinical Ophthalmology. 2014;8:2229-38. doi: 10.2147/OPTH.S70145 pmid: 25419115

21. Khalifa MA, Alsahn MF, Shaheen MS, Pinero DP. Comparative analysis of the efficacy of astigmatic correction after wavefrontguided and wavefront-optimized LASIK in low and moderate myopic eyes. International Journal of Ophthalmology. 2017; 10(2):285-292. doi: 10.18240/ijo.2017.02.17 pmid: 28251090

22. Lee W-S, Manche EE. Comparison of simulated keratometric changes following wavefront-guided and wavefront-optimized myopic laser-assisted in situ keratomileusis. Clinical Ophthalmology. 2018; Volume 12:613-9. doi: 10.2147/OPTH.S161387 pmid: 29636597

23. Roe JR, Manche EE. Prospective, Randomized, Contralateral Eye Comparison of Wavefront-Guided and Wavefront-Optimized Laser in Situ Keratomileusis. American Journal of Ophthalmology. 2019;207:175-83. doi: 10.1016/j.ajo.2019.05.026 pmid: 31173739 
24. Stonecipher K, Parrish J, Stonecipher M. Comparing wavefront-optimized, wavefront-guided and topography-guided laser vision correction. Current Opinion in Ophthalmology. 2018;29(4):277-85. doi: 10.1097/ICU.0000000000000495 pmid: 29787391

25. Racine L, Wang L, Koch DD. Size of Corneal Topographic Effective Optical Zone: Comparison of Standard and Customized Myopic Laser In Situ Keratomileusis. American Journal of Ophthalmology. 2006;142(2):227-32. doi: 10.1016/j.ajo.2006.03.023 pmid: 16876501

26. Smolek MK, Klyce SD, Hovis JK. The Universal Standard Scale. Ophthalmology. 2002;109(2):361-9. doi: 10.1016/s01616420(01)00888-0 pmid: 11825824

27. Partal AE, Manche EE. Diameters of topographic optical zone and programmed ablation zone for laser in situ keratomileusis for myopia. J Refract Surg. 2003 19(5):528-33. pmid: 14518741

28. Meidani A, Tzavara C. Comparison of efficacy, safety, and predictability of laser in situ keratomileusis\&nbsp; using two laser suites. Clinical Ophthalmology. 2016;Volume 10:1639-46. doi: 10.2147/OPTH.S110626 pmid: 27601880

29. Hassan A, Massoud T, Nouby G, Fathlla A. Comparison of visual outcomes and higher order aberrations of wavefront-optimized and wavefront-guided myopic laser in-situ keratomileusis. The Egyptian Journal of Cataract and Refractive Surgery. 2017;23(1):1. doi: 10.4103/JCRS.JCRS_6_17

30. Mahmoud G, Massoud T, Fathlla A, Ahmed A. Evaluation of visual and refractive outcomes of wavefront optimized versus wavefront guided laser-assisted in situ keratomileusis in patients with myopia and myopic astigmatism. Journal of Current Medical Research and Practice. 2017;2(2):111-8. doi: 10.4103/JCMRP.JCMRP_4_17

31. Ghoneim A, Wasfy T, Abass S, Elbedewy H, Khater M, Khalifa M, et al. Comparative analysis of outcomes after wavefront-guided and wavefront-optimized laser in-situ keratomileusis in high myopic eyes. The Egyptian Journal of Cataract and Refractive Surgery. 2018;24(1):1. doi: 10.4103/JCRS.JCRS_16_17

32. Reed DS, Apsey D, Steigleman W, Townley J, Caldwell M. Retrospective Analysis of the Post-Operative Changes in HigherOrder Aberrations: A Comparison of the WaveLight EX500 to the VISX S4 Laser in Refractive Surgery. Military Medicine. 2017;182(11):e2061-e5. doi: 10.7205/MILMED-D-17-00159 pmid: 29087882

33. Bottos KM, Leite MT, Aventura-Isidro M, Bernabe-Ko J, Wongpitoonpiya N, Ong-Camara NH, et al. Corneal asphericity and spherical aberration after refractive surgery. Journal of Cataract and Refractive Surgery. 2011;37(6):1109-15. doi: 10.1016/j. jcrs.2010.12.058 Erratum in: J Cataract Refract Surg. 2011 Sep;37(9):1742. pmid: 21596254.

34. Molchan RP, Taylor KR, Panday VA, Caldwell MC, Reilly CD. Retrospective Analysis Comparing the Preoperative and Postoperative "Q" Values for 2 Different Lasers in Refractive Surgery. Cornea. 2015;34(11):1437-40. doi: 10.1097/ ICO.0000000000000611 pmid: 26356749 